\title{
CHARACTERIZATION OF THREE-DIMENSIONAL PRINTED COMPOSITE SCAFFOLDS PREPARED WITH DIFFERENT FABRICATION METHODS
}

\begin{abstract}
An optimal method for composites preparation as an input to rapid prototyping fabrication of scaffolds with potential application in osteochondral tissue engineering is still needed. Scaffolds in tissue engineering applications play a role of constructs providing appropriate mechanical support with defined porosity to assist regeneration of tissue. The aim of the presented study was to analyze the influence of composite fabrication methods on scaffolds mechanical properties. The evaluation was performed on polycaprolactone (PCL) with $5 \mathrm{wt} \%$ beta-tricalcium phosphate (TCP) scaffolds fabricated using fused deposition modeling (FDM). Three different methods of PCL-TCP composite preparation: solution casting, particles milling, extrusion and injection were used to provide material for scaffold fabrication. The obtained scaffolds were investigated by means of scanning electron microscope, $\mathrm{x}$-ray micro computed tomography, thermal gravimetric analysis and static material testing machine. All of the scaffolds had the same geometry (cylinder, $4 \times 6 \mathrm{~mm})$ and fiber orientation $\left(0 / 60 / 120^{\circ}\right)$. There were some differences in the TCP distribution and formation of the ceramic agglomerates in the scaffolds. They depended on fabrication method. The use of composites prepared by solution casting method resulted in scaffolds with the best combination of compressive strength $(5.7 \pm 0.2 \mathrm{MPa})$ and porosity $(48.5 \pm 2.7 \%)$, both within the range of trabecular bone.
\end{abstract}

Keywords: polycaprolactone, tricalcium phosphate, scaffold, rapid prototyping, tissue engineering, computed tomography

\section{Indroduction}

Nowadays medicine needs materials to support healing and regeneration of critical defects of the affected tissues. It often involves creation of novel three dimensional biomaterials, what is becomes a task for the materials engineers. They have to construct materials with special structure and properties which depend on specific application. From medical point of view, the problem is more difficult. The interaction between biological environment and product of tissue engineering depends on features of an individual organism (Tadeusiewicz \& Augustyniak, 2009; Swieszkowski et al, 2007).

Tissue engineering is an interdisciplinary field that draws from materials science, cell biology, and biotechnology to synthesize effective strategies for repair or replacement of damaged or diseased tissues (Langer \& Vacanti, 1993). The aim of bone tissue engineering is to design a scaffold to regenerate large skeletal defects. Scaffold-guided tissue engineering has been developed to regenerate specific and functional human tissues or organs (Patrick et al, 1998; Hutmacher, 2000). Several techniques have been developed to introduce a degree of porosity in composite scaffolds including fiber bonding (Sang Jin Lee et al, 2008) solvent casting (Hariraksapitak et al, 2008), particulate leaching ( $\mathrm{Hu}$ et al, 2013) and gas foaming (Poursamar et al, 2015). However, these techniques have many disadvantages such as long fabrication time, poor repeatability, irregularly shaped pores, insufficient interconnectivity of pores, restrictions on shape control, etc. Rapid prototyping (RP) methods of 3D printing are viable alternative for achieving extensive and detailed control over scaffold architecture. The RP is fast becoming the technologies of choice for fabricating scaffolds for bone tissue engineering due to the reliability and high degree of reproducibility (Arafat et al, 2011). Complex scaffold architecture designs based on a hierarchical approach can be readily fabricated through RP (Hutmacher et al, 2004; Hollister, 2005). The fused deposition modeling (FDM) is a promising RP technique which has been used to fabricate both polymeric and polymer/ceramic composite scaffolds (Wang et al, 2004; Shor et al, 2007).

The aim of the study was to evaluate the influence of composite prefabrication method on scaffold mechanical properties. The composites were prefabricated using three different methods: solution casting, particles milling, extrusion and injection. The prepared materials were used as pellets in 3D printing process in Bioscaffolder (Syseng, Germany). The fabricated scaffold were characterized for their structure and mechanical properties.

\section{Materials and methods}

\subsection{Preparation of pellets for Bioscaffolder}

Polycaprolactone (PCL, Sigma-Aldrich, particle size ab. $3 \mathrm{~mm}$ ) with $5 \mathrm{wt} \%$ tricalcium phosphate (TCP, Progentix, two

* WARSAW UNIVERSITY OF TECHNOLOGY, FACULTY OF MATERIALS SCIENCE AND ENGINEERING, 141 WOLOSKA STR., 02-507 WARSAW, POLAND

** CZESTOCHOWA UNIVERSITY OF TECHNOLOGY, INSTITUTE OF PHYSICS, 19 ARMII KRAJOWEJ AV., 42-200 CZESTOCHOWA, POLAND

*** CZESTOCHOWA UNIVERSITY OF TECHNOLOGY, INSTITUTE OF MATERIALS SCIENCE AND ENGINEERING, 19 ARMII KRAJOWEJ AV., 42-200 CZESTOCHOWA, POLAND

\# Corresponding author: karolszlazak@wp.pl 


\subsection{Morphology observation by SEM}

fractions 0.18 and $2.5 \mu \mathrm{m}$ particle size) was used to produce
composite scaffolds. Three different methods of composite preparation were investigated: solution casting (SC), particles milling (PM), extrusion and injection (EI).

SC prefabrication method relied on adding $5 \mathrm{wt} \%$ of TCP to PCL and preparing $75 \%$ solution in chloroform (CZDA, Poch Basic). The solution was mixed during two hours on magnetic bar stirrer (Wigo MS $11 \mathrm{HS}$ ) in room temperature. Then the solution was cast on Petri dish and cutting on parts (ab. 4 × 4 × $2 \mathrm{~mm}$ ) after crystallization.

PM prefabrication method relied on milling PCL particles using ultra centrifugal mill (Retsch ZM 200). There was twostages of milling (sieve size $0,75 \mathrm{~mm}$ ):

- first stage: milling with cutting tool rotational speed $10000 \mathrm{rpm}$,

- $\quad$ second stage: milling with cutting tool rotational speed $18000 \mathrm{rpm}$.

To comminuted polycaprolactone was added $5 \mathrm{wt} \%$ of TCP (and mixed using spatula. This method was timeconsuming, because of long milling time: $10 \mathrm{~g} / \mathrm{h}$.

In EI prefabrication method laboratory conical twinscrew extruder (Zamak) and injection moulding machine (Zamak) was used. At the beginning PCL particles was added to extruder container. Above PCL glass temperature TCP (5 $w t \%$ ) was added. Then the composite was mixed during 4 minutes in conditions: temperature $90^{\circ} \mathrm{C}$, screw rotational speed $150 \mathrm{rpm}$ and then extruded. Directly after extruding the material was injected in conditions: cylinder temperature $100^{\circ} \mathrm{C}$, die temperature $32^{\circ} \mathrm{C}$, injection time $10 \mathrm{~s}$, pressure 7 bar. Then the material was cut on parts (ab. $4 \times 4 \times 2 \mathrm{~mm}$ ).

Scaffolds made of pure PCL was also fabricated for comparison. The PCL granules did not required special preparation before printing in Bioscaffolder.

The PCL and PCL-TCP composites before 3D printing were dried for 24 hours in vacuum dryer (Memmert VO 400) in the following conditions: $25^{\circ} \mathrm{C}$ and $25 \mathrm{mb}$.

\subsection{Fabrication of porous scaffolds}

Scaffold geometry was designed in SolidWorks 2008 and then sent to PrimCAM software. The scaffold had cylindrical shape with $4 \mathrm{~mm}$ height and $6 \mathrm{~mm}$ diameter. It consisted of 15 layers and $50 \%$ theoretical porosity, typical for bone regeneration (Mondrinos, et al, 2006). The predesigned fiber lay-down pattern was $0 / 60 / 120^{\circ}$ (Fig. 1.). Printing parameters were set interactively by the user and were the same for all scaffold. Bioscaffolder with needle G23 ( $\varphi 330 \mu \mathrm{m})$ was used to fabricate the scaffolds.

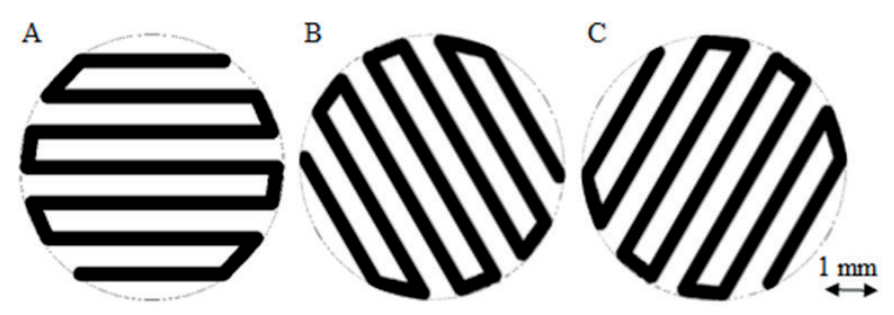

Fig. 1. The angle of the fibers between following coats: $0^{\circ}$ (a), $60^{\circ}$ (b), $120^{\circ}$ (c)
The morphology of PCL-TCP and PCL scaffolds were examined. Before the observations the scaffolds were dried at room temperature overnight. All dried samples without any coating were observed at different magnifications and with acceleration voltages of 10 to $30 \mathrm{kV}$ by SEM (Hitachi S-3500N).

\subsection{Three dimensional structure analysis - microcomputed tomography (micro-CT)}

The prepared scaffolds were examined by means of SkyScan 1172 micro-CT (Bruker) using latest softwares of SkyScan (Bruker). The X-ray parameters, such as voltage, type of filter, exposure time and pixel size were optimized in order to obtain the best image contrast. The X-ray tube voltage was $40 \mathrm{kV}$ and current was $250 \mu \mathrm{A}$. The X-ray projections were obtained at $0.3^{\circ}$ intervals with scanning angular rotation of $180^{\circ}$ and 5 frames were averaged for each rotation. Additionally, ring artefacts were reduced trough selection of a random movement. Exposure time was $100 \mathrm{~ms}$. The obtained pixel size was $4.4 \mu \mathrm{m}$. CTAn (Bruker) was used to calculate the qualitative parameters and creating 3D reconstructions of the scaffolds. CTVol (Bruker) and CTVox (Bruker) were used to show 3D images.

Distribution of TCP agglomerates was measured on fibers cutting from top layer of the scaffolds and observed on Xradia MicroXCT-400. The achieved resolution was $0.56 \mu \mathrm{m}$.

\subsection{Thermogravimetric analysis (TGA) of TCP content in composite scaffolds}

To confirm the $5 \mathrm{wt} \%$ content of TCP in the composite the TGA analysis was performed. The percentage weight losses of scaffolds were analyzed using thermogravimetric analysis (TGA Q5000). The above investigations were carried out over the temperature range $25-700^{\circ} \mathrm{C}$ with a heating rate of $10^{\circ} \mathrm{C}$ min-1.

\subsection{Scaffold mechanical properties}

The compressive strength of the scaffolds were measured using a screw-driven load frame (Zwick-Roell Z005) at a crosshead speed of $1 \mathrm{~mm} / \mathrm{min}$. The compression tests were performed in accordance with PN-EN ISO 604:2006 at room temperature using preloading force set to be $10 \mathrm{~N}$. The force and displacement were recorded during the compression and converted to stress and strain based on the initial scaffold dimensions. Five samples were tested to obtain the average value along with its standard deviation.

\section{Results}

\subsection{SEM imaging}

One of the methods of microstructure analyzing was SEM imaging. A comparison of four fiber structures was 
demonstrated in Figure 2. Images of these representative samples reveal that the fibers were distributed in correct way, while the size of the fiber depended on prefabrication method. Diameters of composite fibers were smaller than PCL fibers. It was due to the effect of higher viscosity in composite scaffolds. Shape of the scaffold fibers were straight, without the EI scaffold fibers. That was largely due to a fact that in the EI method, there was several heat treatments, which could change the properties of the composition. Moreover, there were observed TCP agglomerates, all similar in shape, on the surface of the composite scaffolds .
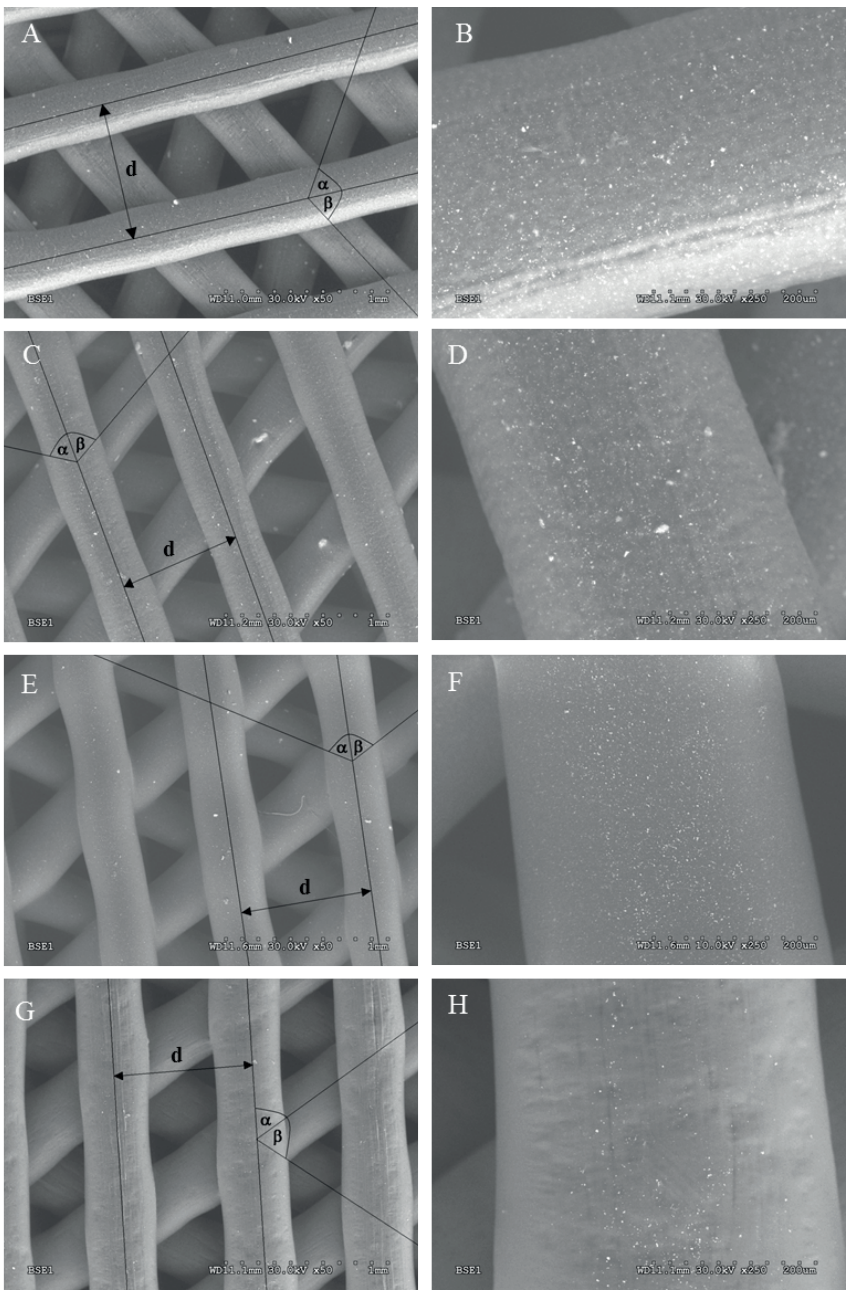

Fig. 2.SEM images of composite scaffolds obtained by solution casting $(a, b)$, particles milling (c, d), extrusion and injection $(e, f)$ prefabrication methods and PCL scaffold $(\mathrm{g}, \mathrm{h})$. Angles in all scaffold were $\alpha=\beta=60.2 \pm 0.1^{\circ}$; diameters between fibers, $d=800.1 \pm 1.5 \mu \mathrm{m}$

\subsection{Micro-CT scans}

The scans were performed on representative samples at each composition of scaffolds. The 3D models of composite and PCL scaffolds were shown in Fig. 3. Pore shape in the PCL scaffolds and scaffolds obtained via SC and PM method were similar (Fig. $3 \mathrm{~A}$ and B, D), whereas irregular pore shape structure was observed in the EM scaffolds (Fig. 3C).

The porosity was determined for each of the materials by volumetric analysis of $3 \mathrm{D}$ reconstructions dataset. Representative slices of scaffolds were shown on Fig. 4. The theoretical porosity was $50 \%$, while measured values were $48.5 \pm 2.7 \%$ for $\mathrm{SC}, 49.4 \pm 3.4 \%$ for PM and $47.4 \pm 2.9 \%$ for EI method while the polymeric scaffolds had $30.1 \pm 2.5 \%$. These results conform fairly well for composite scaffolds (within $<5 \%$ ) to the theoretically calculated porosity. PCL scaffolds had lower porosity probably because of their lower viscosity, which caused an increase in fiber diameter and decrease of pore size in the same time. Closed porosity was also observed, but it was only in composite scaffolds prefabricated by PM method (Fig. 4 B). Closed pores appeared in this method probably because PCL did not pre-wet TCP, creating pores on boundaries. It was a result of using a PCL+TCP powder to Bioscaffolder batch, without any heat treatment being applied before.

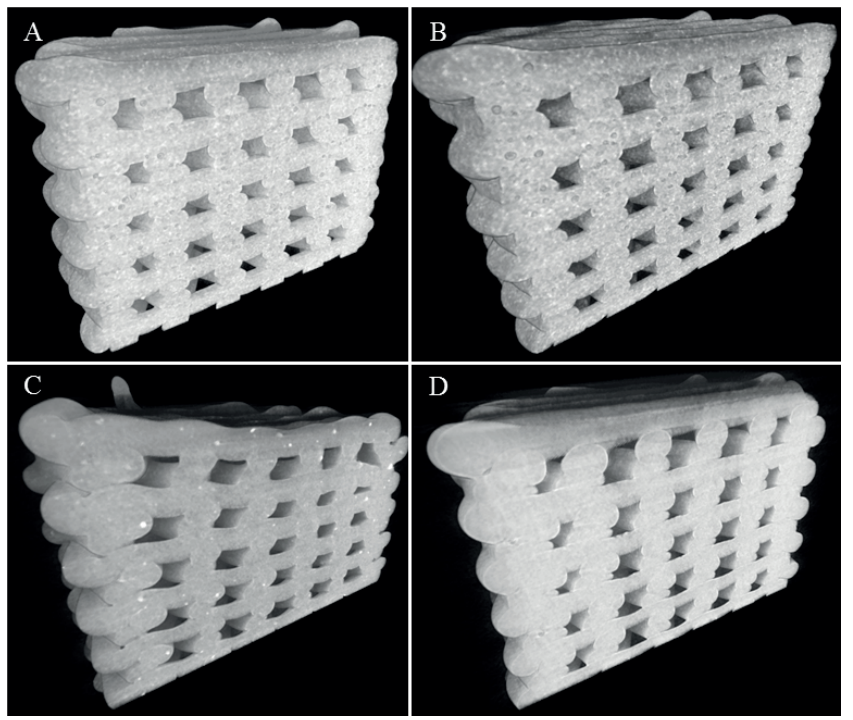

Fig. 3. Microcomputed tomography 3D images (cross section) of composite scaffolds obtained by solution casting (a), particles milling (b), extrusion and injection (c) prefabrication methods and PCL scaffold (d); resolution $4.4 \mu \mathrm{m}$
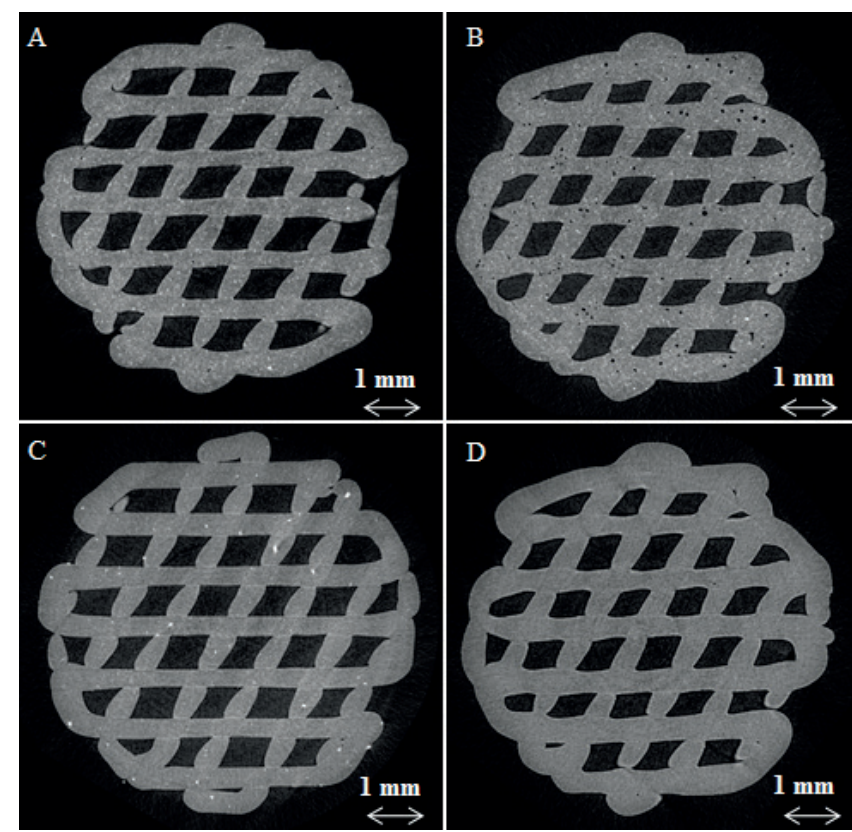

Fig. 4. Microcomputed tomography 2D images (cross sections) of composite scaffolds obtained by solution casting (a), particles milling (b), extrusion and injection (c) prefabrication methods and PCL scaffold (d). Pores are black, TCP particles are white; resolution $4.4 \mu \mathrm{m}$ 


\subsection{Thermogravimetric analysis} (resolution $0.56 \mu \mathrm{m}$ ) on representative samples. The microCT scans were performed on fibers from each scaffolds (Fig. $5)$. The TCP particles were measured by means of $3 \mathrm{D}$ image analysis (Fig. 6). There were observed numerous agglomerates (Fig. 7). Theoretical content of TCP (1.92 vol\%, i.e. $5 \mathrm{wt} \%)$ was even $1.67 \%$ (for PM method) less than measurements made from $\mu \mathrm{CT}$ images. This difference is a result of scan resolution.

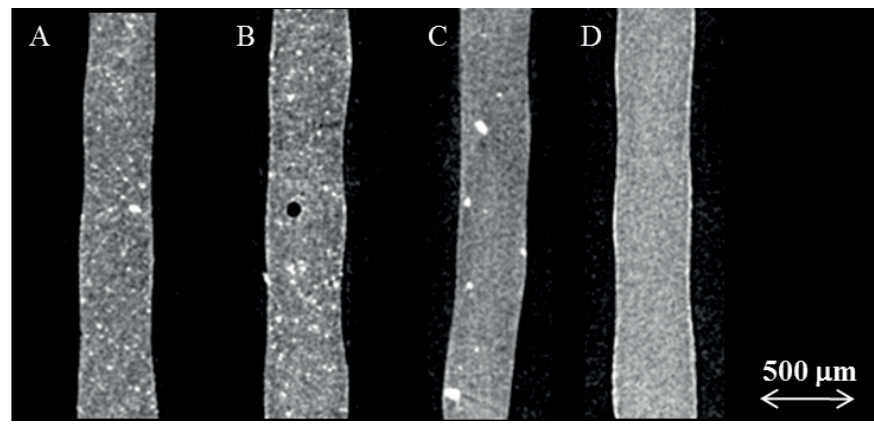

Fig. 5. Microcomputed tomography 2D images (cross section) of composite scaffold fibers obtained by solution casting (a), particles milling (b), extrusion and injection (c) prefabrication methods and PCL scaffold (d). Pores are black, TCP particles are white; resolution $0.56 \mu \mathrm{m}$

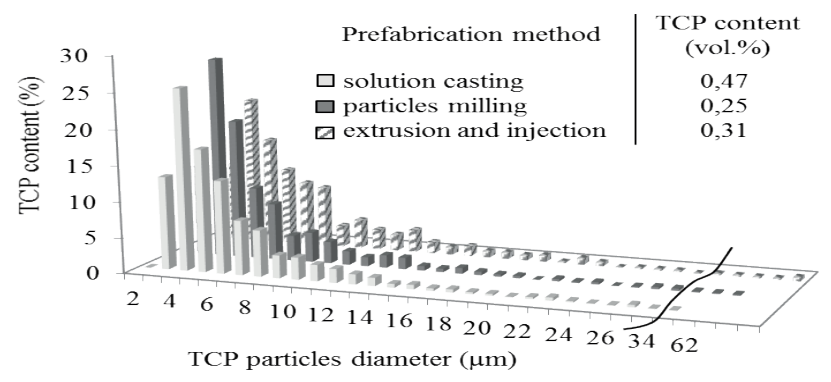

Fig.6. The 3D analysis of TCP content in composite scaffold fibers obtained by solution casting, particles milling, extrusion and injection prefabrication methods

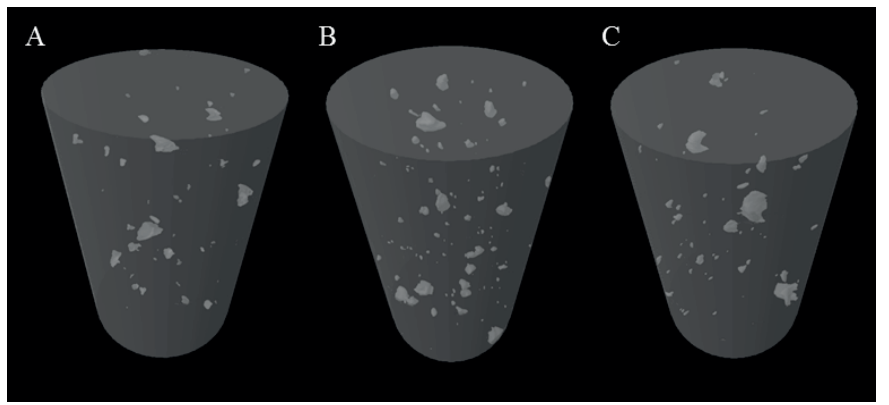

Fig. 7. Microcomputed tomography $3 \mathrm{D}$ reconstrucions of composite scaffold fibers obtained by solution casting (a), particles milling (b), extrusion and injection (c) prefabrication methods, (TCP colored in gray)
To confirm the $5 \mathrm{wt} \%$ content of TCP in the composite scaffolds the TGA analysis was performed. The percentage weight losses of typical composite scaffolds obtained by solution casting method was $95.19 \mathrm{wt} \%$ (Fig. 8). After PCL evaporated process (which stared in ab. $350^{\circ} \mathrm{C}$ ) in composite scaffolds on the weighing machine was only TCP powder. These data conform fairly well for composite scaffolds (within $<4 \%$ ) to the theoretically calculated TCP content $(5 \mathrm{wt} \%)$ - Table 1 .

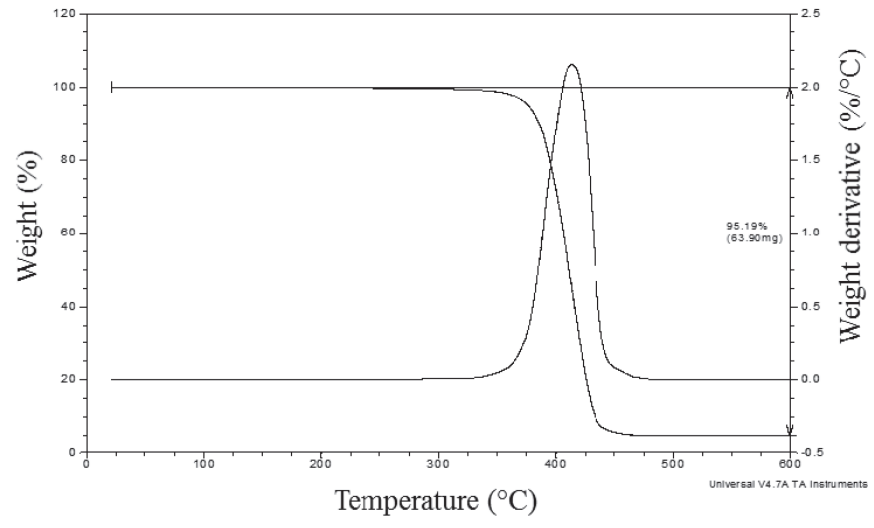

Fig. 8. Thermogravimetric analysis of TCP content in composite scaffold obtained by solution casting prefabrication method

TABLE 1

TCP content in composite scaffolds

\begin{tabular}{|c|c|c|}
\hline \hline Prefabrication method & $\begin{array}{c}\text { TCP content } \\
(\mathrm{wt} \%)\end{array}$ & $\begin{array}{c}\text { Theoretical TCP } \\
\text { content }(\mathrm{wt} \%)\end{array}$ \\
\hline Solution casting & 4.81 & \multirow{2}{*}{5} \\
\hline Particles milling & 5.60 & \\
\hline Extrusion with injection & 5.16 & \\
\hline
\end{tabular}

\subsection{Mechanical properties}

On the grounds of representative stress-strain curves (Fig. 9) there were calculated compressive strength for $0.2 \%$ deformation (Table 2). No significant differences in pore size distribution have been observed in the composite scaffolds, indicating that all these samples had the similar porous structure, which did not make contributions to the improvement in the compressive strength. Only PCL scaffold had lower porosity indicating higher compressive strength. However, the compressive strength for all of the scaffolds was in value typical for trabecular bone from human mandibles ranging from 0.22 to $10.44 \mathrm{MPa}$ (Misch et al. 1999).

TABLE 2

Compressive strength (calculated for $0.2 \%$ deformation) of composite and PCL scaffolds

\begin{tabular}{|c|c|}
\hline \multicolumn{2}{|c|}{} \\
\hline Prefabrication method & Compressive strength $[\mathrm{MPa}]$ \\
\hline Solution casting & $5.7 \pm 0.2$ \\
\hline Particles milling & $4.9 \pm 0.3$ \\
\hline Extrusion with injection & $6.0 \pm 0.2$ \\
\hline
\end{tabular}




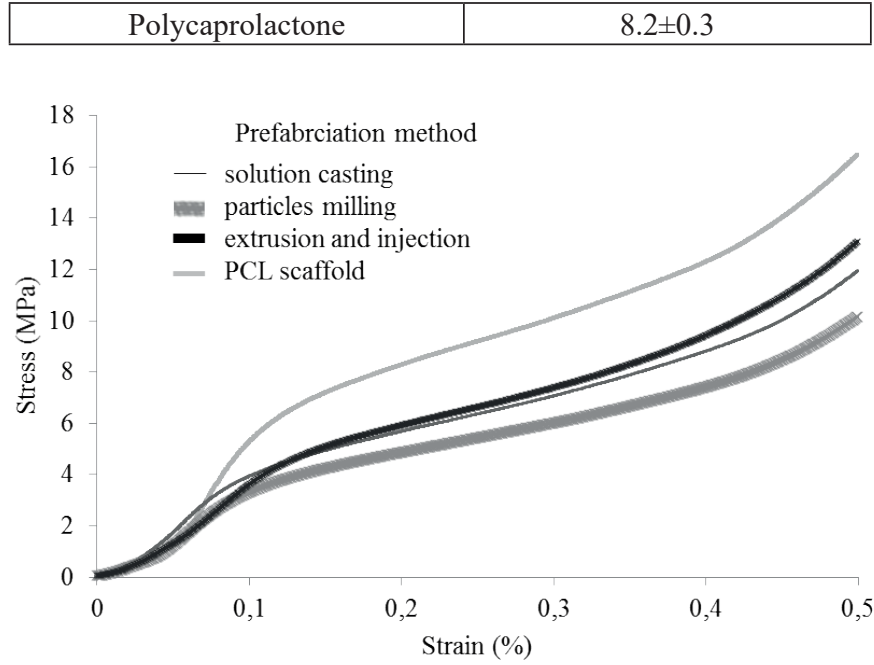

Fig. 9. Stress-strain curves of composite and PCL scaffolds

\section{Conclusions}

Composite preparation method has a significant impact on scaffolds quality and properties. Particles milling method is time-consuming and the scaffolds prefabricated using this method for PCL-TCP composite preparation results in constructs with closed pores and low compressive strength. On the other hand scaffolds prefabricated using material from extrusion and injection method have irregular shape due to several heat treatments and large agglomerates causing increase of compressive strength. The best combination of quality and properties was obtained for scaffolds made of composite produced using solution casting method. These scaffolds have compressive strength of $5.7 \pm 0.2 \mathrm{MPa}$ and porosity of $48.5 \pm 2.7 \%$, both within the range of trabecular bone. Therefore solution casting is a promising method to prepare PCL-TCP composite material for fabrication of scaffolds suitable for bone regeneration. The future study should be focus on in vitro and in vivo evaluation on the most encouraging scaffolds.

\section{Acknowledgements}

This work has been supported by the National Science Centre no. DEC2012/07/D/ST8/02606 and partially by Bioimplant project (Grant No. POIG.01.01.02-00-022/09).

\section{REFERENCES}

[1] R.Tadeusziewicz, P. Augustyniak, Basic Biomedical Engineering 2, AGH, Kraków 2009.

[2] W. Swieszkowski, Ho Saey Tuanb Barnabas, K.J. Kurzydlowski, D.W. Hutmacher, Repair and regeneration of osteochondral defects in the articular joints, Biomolecular Engineering 24, 5, 489-495 (2007).

[3] R. Langer, J. Vacanti, Tissue engineering, Science 260, 920926(1993).

[4] C.W. Patrick, A.G. Mikos, L.V. Mcintire, Frontiers in Tissue Engineering, New York, Pergamon 1998.

[5] D.W. Hutmacher, Scaffolds in tissue engineering bone and cartilage Biomaterilas 21, 2529-43 (2000).

[6] S.J. Lee, S.H. Oh, J. Liu, S. Soker, A. Atala, J.J. Yoo, The use of thermal treatments to enhance the mechanical properties of electrospun poly(É-caprolactone) scaffolds, Biomaterials 29, 10, 1422-1430 (2008).

[7] P. Hariraksapitak, O. Suwantong, P. Pavasant, P. Supaphol, Effectual drug-releasing porous scaffolds from 1,6-diisocyanatohexane-extended poly(1,4-butylene succinate) for bone tissue regeneration, Polymer 49, 11, 26782685 (2008).

[8] C. Hu, C. Tercero, S. Ikeda, M. Nakajima, H. Tajima, Y. Shen, T. Fukuda, A. Fumihito, Biodegradable porous sheetlike scaffolds for soft-tissue engineering using a combined particulate leaching of salt particles and magnetic sugar particles, Journal of Bioscience and Bioengineering 116, 1, 126-131 (2013).

[9] S.A. Poursamara, J. Hatamic, A.N. Lehnerb, C.L. Silvac, F.C. Ferreirac, A.P.M Antunesa, Gelatin porous scaffolds fabricated using a modified gas foaming technique: Characterisation and cytotoxicity assessment, Materials Science and Engineering: C 48, 63-70 (2015).

[10] M.T. Arafat, C.X.F. Lam, A.K. Ekaputra, S.Y. Wong, X. Li, I. Gibson, Biomimetic composite coating on rapid prototyped scaffolds for bone tissue engineering, Acta Biomaterialia 7, 2, 809-820 (2011)

[11] D.W. Hutmacher, M. Sittinger, M. V. Risbud Scaffold-based tissue engineering: rationale for computer-aided design and solid free-form fabrication systems, Trends Biotechnol 22, 354-362 (2004)

[12] S. J. Hollister Porous scaffold design for tissue engineering, Nat Mater 4, 518-524 (2005).

[13] F. Wang, L. Shor, A. Darling, S. Khalil, W. Sun, S. Guceri et al. Precision extruding deposition and characterization of cellular poly-Îl'-caprolactone tissue scaffolds, Rapid Prototyping J 10, 42-49 (2004).

[14] L. Shor, S. Guceri, X. Wen, M. Gandhi, W. Sun Fabrication of three-dimensional polycaprolactone/hydroxyapatite tissue scaffolds and osteoblastâscaffold interactions in vitro, Biomaterials 28, 5291-5297 (2007).

[15] M.J. Mondrinos, R. Dembzynski, L. Lu, V. K. C. Byrapogu, D.M. Wootton, P.I. Lelkes, J. Zhou, Porogen-based solid freeform fabrication of polycaprolactoneâcalcium phosphate scaffolds for tissue engineering, Biomaterials 27, 25, 43994408 (2006)

[16] C.E. Misch, Z. Qu, M. W. Bidez, Mechanical properties of trabecular bone in the human mandible: implications for dental implant treatment planning and surgical placement, J Oral Maxillofac Surg 57 (6), 700-706. (1999). 
